\title{
Inclusão excludente e utopia digital: a formação docente no Programa Um Computador por Aluno ${ }^{1}$
}

\section{Excluding inclusion and digital utopia: teacher formation in the Program A Computer for each Student}

\author{
Adda Daniela Lima Figueiredo Echalar ${ }^{2}$ \\ Joana Peixoto ${ }^{3}$
}

\begin{abstract}
RESUMO
Este artigo discute as questões que emergiram em uma pesquisa sobre a formação de professores para a inclusão digital via ambiente escolar no contexto do Programa Um Computador por Aluno no estado de Goiás. Estas questões são abordadas através da convergência de dois eixos temáticos: 1) a formação de professores e a 2) inclusão digital via ambiente escolar, com base em princípios do materialismo histórico-dialético. A contradição e a alienação são utilizadas para colocar em questão o conceito de inclusão digital e para demonstrar que o modelo formativo docente teve como
\end{abstract}

DOI: $10.1590 / 0104-4060.46088$

1 Este texto se constitui em desdobramento de tese de doutorado (ECHALAR, 2015) e de pesquisa financiada pelo Edital da Fundação de Amparo à Pesquisa do Estado de Goiás (FAPEG)/ Universal 005/2012. (FIGUEIREDO, 2013). Esta última desenvolvida no contexto da Rede Goiana de Pesquisa em Políticas Públicas e Inclusão Digital (REPPID) / FAPEG e do Kadjót, cadastrado no Diretório do Conselho Nacional de Desenvolvimento Científico e Tecnológico (CNPq): $<$ https:// sites.google.com/site/grupokadjotgoiania/>.

2 Universidade Federal de Goiás. Programa de Pós-Graduação em Educação em Ciências e Matemática. Goiânia, Goiás, Brasil. Campus Samambaia. ICB IV - Sala 1 - Setor Itatiaia. CEP: 74.001-970.E-mail: addadani@gmail.com

3 Instituto Federal de Educação, Ciência e Tecnologia de Goiás. Programa de Pós-Graduação Profissional em Educação para Ciências e Matemática. Pontifícia Universidade Católica de Goiás. Programa de Pós-Graduação em Educação. Goiânia, Goiás, Brasil. Rua 75, nº 46 - Setor Central, CEP: 74055-110.E-mail: joanagynn@gmail.com 
pressupostos básicos a fragmentação e a hierarquização, baseando-se em uma racionalidade instrumental.

Palavras-chave: materialismo histórico-dialético; formação de professores; inclusão digital via ambiente escolar; laptops educacionais; tecnologia e educação.

\begin{abstract}
This article discusses the issues that emerged from a research on teacher formation for digital inclusion via school environment in the context of the Program A Computer for each Student in Goiás, Brazil. These issues are addressed through the convergence of two themes: 1) teacher formation; 2) digital inclusion via school environment, based on principles of historical and dialectical materialism. The principles of contradiction and alienation are adopted to bring into question the concept of digital inclusion and to demonstrate that the teacher formation model had as its basic assumptions fragmentation and hierarchization, based on an instrumental rationality.

Keywords: historical and dialectical materialism; teacher formation; digital inclusion via school environment; educational laptops; technology and education.
\end{abstract}

\title{
Introdução
}

Dentre os programas do governo federal brasileiro de inclusão digital via ambiente escolar, o Programa Um Computador por Aluno (PROUCA) foi proposto em 2005 como estratégia para a redução das desigualdades sociais. Denominado num primeiro momento como Projeto UCA, em sua fase inicial esteve vinculado à distribuição de laptops em cinco escolas-modelo no país. $\mathrm{O}$ nome Projeto UCA foi modificado para Programa Um Computador por Aluno (PROUCA) em 2010, quando se instaurou a Lei n. 12.249, de 10 de junho de 2010, que o cria e o regulamenta.

Do momento da apresentação da proposta do Projeto ao governo brasileiro até sua implantação, foi instituído um Grupo de Trabalho de Assessoramento Pedagógico do UCA(GTUCA) com os objetivos de assessorar pedagogicamente a elaboração do documento básico do projeto e de realizar o acompanhamento e a avaliação das cinco escolas-modelo que compuseram a fase pré-piloto, chamada fase I, de sua implantação no país. No momento da implementação 
do PROUCA fez-se a expansão do Programa a 300 escolas do país, passando à fase II ou também chamada de Piloto. Atualmente, o Programa não recebe novos custeios ou fases de implementações, mas também não foi oficialmente extinto.

O GTUCA foi composto por membros da extinta Secretaria de Educação a Distância do Ministério da Educação (SEED/MEC) e por assessores pedagógicos de distintas instituições de Ensino Superior (IES) do Brasil. O processo de implantação, acompanhamento e avaliação do Programa em cada escola ocorreu de forma hierárquica e sequencial, envolvendo as 27 unidades federativas do país e as IES de cada estado (denominadas IES Locais), sendo assim organizado conforme apresentado no Quadro 1.

No que tange à formação de professores, o grupo instituiu o material denominado "Formação Brasil: projeto, planejamentos das ações/cursos" (BRASIL, 2009), que apresenta as diretrizes dos cursos de formação. O período de dois anos foi considerado o tempo mínimo para que os educadores se capacitassem para trabalhar pedagogicamente com os recursos digitais, em 36 horas presenciais e 144 horas a distância. (BRASIL, 2009).

Buscamos aqui superar a mera constatação das fragilidades anteriormente citadas, já fartamente apontadas em investigações sobre esse e outros programas educacionais brasileiros (ECHALAR, 2015; GOMES, 2010; MARQUES, 2009; MOREIRA, 2010; SARIAN, 2012; SANTOS, 2010). Por esta razão, o exercício de compreensão desta realidade concreta representada por este Programa de governo nos remeteu à reconstrução dos contextos nos quais ele se insere e as políticas neoliberais que o alicerçam. Com base nos princípios do materialismo dialético (MARX; ENGELS, 2007), tomamos o processo formativo dos professores para a inclusão digital a partir do processo de implantação do PROUCA no estado de Goiás, como parte da totalidade que aí se reflete: as relações materiais e ideológicas de um determinado tempo histórico.

Buscaremos demonstrar que o PROUCA nos remete a um processo de inclusão digital via ambiente escolar que visa eminentemente o adensamento da cadeia produtiva de empresas que são parceiras dos organismos internacionais que financiam e ditam as regras de nosso sistema educativo. Assim, ele se situa no escopo de uma política nacional que renova a utopia técnica, em que se defende o acesso à tecnologia e à informação em detrimento de uma política social articulada à realidade das escolas brasileiras.

O discurso de inclusão digital presente nos documentos oficiais do PROUCA evidencia um processo de inclusão excludente (termo proposto por Martins em 1997), já que não promove a superação da condição de alienação da classe trabalhadora que não vivencia um acesso racional às tecnologias digitais.

A pesquisa foi desenvolvida no período de 2011 a 2014, envolvendo uma fase exploratória, a pesquisa de campo e a análise documental. A fase inicial da 
QUADRO 1 - ESTRUTURA ORGANIZACIONAL DE IMPLANTAÇÃO DO PROUCA NO BRASIL

\begin{tabular}{|c|}
\hline $\begin{array}{l}\text { QUEM: } \\
\text { Membros da SEED/MEC e do GTUCA }\end{array}$ \\
\hline $\begin{array}{l}\text { ATRIBUIÇÕES: } \\
\text { Assessoria pedagógica e elaboração do documento básico do projeto. } \\
\text { Acompanhamento e avaliação das escolas-modelo (Fase I de implantação). } \\
\text { Ação 1: Preparação da equipe de formação dos representantes do } \\
\text { GTUCA nas IES globais. }\end{array}$ \\
\hline Љ \\
\hline $\begin{array}{l}\text { QUEM: } \\
\text { Membros das Instituições de Ensino Superior (IES) globais (universidades que } \\
\text { possuem assessores pedagógicos do GTUCA em seu corpo docente) }\end{array}$ \\
\hline $\begin{array}{l}\text { ATRIBUIÇÕES: } \\
\text { Ação 2: Preparação da equipe de formação dos membros das IES locais, SE e } \\
\text { Tecnologia Educacional Estadual (NTE)/ Núcleos de Tecnologia Educacional } \\
\text { Municipais (NTM). }\end{array}$ \\
\hline Љ \\
\hline $\begin{array}{l}\text { QUEM: } \\
\text { Instituições de Ensino Superior (IES) locais (universidades que possuem docentes } \\
\text { que, em parceria com as IES globais, integram o grupo de formação e pesquisa), } \\
\text { Secretarias de Educação (SE), Núcleos de Tecnologia Educacional Estadual (NTE), } \\
\text { Núcleos de Tecnologia Educacional Municipais (NTM). }\end{array}$ \\
\hline $\begin{array}{l}\text { ATRIBUIÇ ÕES: } \\
\text { Ação 3: Formação dos professores e gestores nas escolas (Fase II). }\end{array}$ \\
\hline$\checkmark$ \\
\hline $\begin{array}{l}\text { QUEM: } \\
\text { A ser definido com secretarias e escolas locais. }\end{array}$ \\
\hline $\begin{array}{c}\text { ATRIBUIÇÕES: } \\
\text { Ação 4: Formação dos alunos-monitores. }\end{array}$ \\
\hline Љ \\
\hline $\begin{array}{l}\text { QUEM: } \\
\text { Professores, gestores e alunos. }\end{array}$ \\
\hline $\begin{array}{l}\text { ATRIBUIÇÕES: } \\
\text { Execução das ações previstas (público-alvo final). }\end{array}$ \\
\hline
\end{tabular}

FONTE: Adaptado de Brasil (2009). 
pesquisa caracterizou-se por um estudo exploratório - realizado em pesquisa coordenada pela Rede Goiana de Pesquisa em Políticas Públicas e Inclusão Digital (REPPID) - que ocorreu em visitas a quatro das escolas contempladas pelo Programa. Concomitante à fase exploratória, iniciamos a coleta de documentos oficiais.

Cientes de que os documentos não são suficientes para compreender o contexto de uma política pública, fez-se necessário ir a campo para buscar explicações das particularidades do nosso objeto de estudo. Nesta fase, foram visitadas as nove escolas participantes do PROUCA no estado de Goiás.

Durante o trabalho de campo, realizamos entrevistas semiestruturadas e observações in loco. Além disso, trabalhamos com registros escritos de conversas não gravadas; mensagens trocadas por correio eletrônico; notas de campo; materiais audiovisuais; blogs; textos e/ou reportagens sobre os temas publicados em jornais e revistas e, ainda, dados de outras pesquisas sobre o mesmo tema ou afins.

Foram entrevistados 55 professores e gestores de escolas contempladas pelo PROUCA em Goiás, dentre aqueles que iniciaram ou concluíram a formação ofertada pelo Núcleo de Tecnologia Educacional (NTE) ou pelos representantes do GTUCA da Universidade Federal de Goiás (UFG).

O percurso metodológico traçou uma reflexão sobre a realidade da inclusão digital via ambiente escolar que partiu do empírico, uma realidade dada, o objeto assim como ele se apresentava: o PROUCA no estado de Goiás. Por meio de abstrações - elaborações do pensamento que buscaram conceitos ancorados numa teoria - buscou-se o concreto pensado, uma compreensão mais elaborada do que há de essencial no objeto.

Seguindo esse percurso, o artigo em tela está organizado em três seções. A primeira discute a particularidade da fragmentação do processo formativo docente no contexto do PROUCA no Brasil e no estado de Goiás. Na segunda seção, recorremos ao princípio da contradição para colocar em questão o próprio conceito de inclusão digital. E a terceira seção destaca a alienação como elemento explicativo para um processo formativo preponderante prático e instrumental.

\section{A fragmentação e a hierarquização como prerrogativas para a formação docente}

A hierarquização da formação docente, ilustrada no Quadro 1, pode ser bem observada no caso do PROUCA no estado de Goiás, onde a equipe men- 
tora da formação é constituída pelos membros do GTUCA e que compõem as instituições globais que coordenam o processo. No estado de Goiás, a equipe da Pontifícia Universidade Católica de São Paulo (PUCSP) é a IES global e o Laboratório de Tecnologia da Informação e Mídias Educacionais da instituição responsável local, a Universidade Federal de Goiás (UFG).

A equipe de formação na escola é o Núcleo de Tecnologia Educacional (NTE) do estado de Goiás. Os conteúdos propostos pela equipe mentora deveriam ser multiplicados pela equipe da instituição responsável local aos formadores dos NTE do estado e, a partir destes, serem reproduzidos para os professores em cada escola do Programa.

O processo de implementação do PROUCA nas escolas goianas aconteceu em tempos e formas distintas. Identificamos que a fragmentação - que foi uma característica marcante deste processo formativo - se manifestou em duas formas: a hierarquização do processo formativo e a organização curricular modular do curso.

As ações que integram o PROUCA, inclusive a formação docente, são marcadas por determinações de caráter econômico segundo um viés economicista do Banco Mundial e demais instituições multilaterais que influenciam as políticas educacionais em nosso país. De acordo com tais instituições, a formação em serviço é a estratégia mais eficaz para melhor capacitar os professores e diminuir o custo do processo. Com tal indicação, o Banco Mundial prega uma visão utilitarista e fragmentada para a ação. A flexibilização da formação, o estímulo ao desenvolvimento de competências, o aprender a aprender, o atendimento à diversidade, a centralidade da prática e a predominância de carga horária a distância são características comuns deste tipo de formação docente.

Essa proposta formativa se caracteriza por uma divisão social e técnica do trabalho, demarcando as fronteiras entre ações intelectuais e instrumentais, inclusive no âmbito escolar: os integrantes do GTUCA são encarregados de conceber e planejar, enquanto cabe aos professores executar as atividades inerentes ao Programa.

Assim, esse percurso evidencia a dicotomia entre os intelectuais formuladores de propostas educacionais e seus executores na escola. Embora seu discurso dê ênfase ao papel do professor, o governo não permite que ele participe efetivamente das proposições para a sua formação.

A formação modular é outro aspecto que caracteriza a referida fragmentação aliada à produção em massa para diminuir gastos. Cada módulo se organiza em unidades sequenciáveis pelas quais uma etapa seria necessariamente pré-requisito para a outra. 
No PROUCA, a formação para os professores, em sua parte a distância, ocorre por meio do e-ProInfo $2^{4}$ e foi dividida em quatro módulos, conforme Quadro 2:

QUADRO 2 - ORGANIZAÇÃO DE CONTEÚDOS DA PARTE REALIZADA A DISTÂNCIA DO CURSO DE FORMAÇÃO DE PROFESSORES (PROUCA)

\begin{tabular}{|c|c|c|c|c|}
\hline & \multicolumn{4}{|c|}{ MÓDULOS } \\
\hline & I & II & III & IV \\
\hline 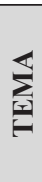 & $\begin{array}{l}\text { Compreensão do } \\
\text { projeto UCA e } \\
\text { apropriação dos } \\
\text { recursos do laptop. }\end{array}$ & $\begin{array}{l}\text { Inovação } \\
\text { pedagógica } \\
\text { no uso de } \\
\text { tecnologias } \\
\text { digitais. }\end{array}$ & $\begin{array}{c}\text { Atualização do } \\
\text { Projeto Político- } \\
\text { Pedagógico (PPP) da } \\
\text { escola para incluir as } \\
\text { tecnologias digitais. }\end{array}$ & $\begin{array}{l}\text { Socialização } \\
\text { da proposta do } \\
\text { UCA da escola. }\end{array}$ \\
\hline 号 & $\begin{array}{l}\text { - Conhecendo o } \\
\text { Linux e o KOffice; } \\
\text { - Navegadores; } \\
\text { - Ferramentas de } \\
\text { busca; } \\
\text { - Recursos do } \\
\text { laptop. }\end{array}$ & $\begin{array}{l}\text { - Práticas } \\
\text { pedagógicas } \\
\text { utilizando } \\
\text { Web 2.0; } \\
\text { - construção do } \\
\text { blog. }\end{array}$ & $\begin{array}{l}\text { - Reelaborando o } \\
\text { PPP da escola; } \\
\text { - Reflexões sobre } \\
\text { a pedagogia da } \\
\text { descoberta a partir } \\
\text { de sua experiência } \\
\text { pessoal; } \\
\text { - Elaboração de } \\
\text { um projeto de } \\
\text { aprendizagem. }\end{array}$ & $\begin{array}{l}\text { - Conhecimento } \\
\text { do trabalho } \\
\text { de alguns } \\
\text { pesquisadores } \\
\text { da área de } \\
\text { educação; } \\
\text { - Produção do } \\
\text { memorial } \\
\text { sobre o curso; } \\
\text { - Apresentação } \\
\text { dos resultados } \\
\text { do projeto na } \\
\text { escola. }\end{array}$ \\
\hline
\end{tabular}

FONTES: Brasil (2009) e dados da pesquisa empírica.

Observamos que os módulos são definidos como unidades autônomas e completas em si mesmas, sendo capazes de conferir competência ou habilitação para uma ação prática do sujeito.

Pela fala dos entrevistados, percebemos que a passagem de um módulo a outro durante o processo formativo se deu em função de uma periodização baseada em datas pré-definidas e não pela superação do conteúdo de cada etapa. Isso porque as atividades na plataforma do e-ProInfo eram pré-determinadas quanto ao conteúdo e ao tempo de duração, não levando em consideração o contexto social e de aprendizagem dos diversos professores nas distintas localidades do estado de Goiás.

4 A plataforma do e-ProInfo (Programa Nacional de Tecnologia Educacional - ProInfo) é um ambiente virtual de aprendizagem criado pelo MEC para oportunizar formações aos professores e alunos de escolas públicas brasileiras. 
Os módulos condicionados por um tempo pré-determinado, aliados ao processo de certificação que garante benefício financeiro ao docente, imprimem ao processo formativo a lógica de acumulação e produtividade. Esta, no sistema de formação, traveste-se em uma falsa acumulação do saber. Podemos deduzir daí um processo de alienação por meio do qual o professor não se reconhece como sujeito do seu processo formativo, já que a certificação não expressa a trajetória de seus estudos e muito menos o conhecimento por ele apropriado.

O processo formativo modular tem bases tayloristas-fordistas, também chamado por Freitas (2011) de neotecnicismo, sendo constituído por conhecimentos factuais a serem reproduzidos pelos trabalhadores. O método de ensino, aprendizagem e treinamento se baseia na flexibilidade, polivalência e intensificação do trabalho, já que ocorre em serviço.

Na busca por compreender melhor as denominadas "habilidades portáteis", retomamos o questionamento da pesquisa sobre o material didático do curso para formação dos professores e gestores, proposto pelo PROUCA em Goiás. Os 55 entrevistados alegam que este material destinou-se ao ensino do manuseio do laptop (hardware e softwares) e de alguns aplicativos da internet, como o e-mail e o blog. Além de apresentar os softwares e objetos de aprendizagem disponíveis no computador portátil.

Cerca de 230 docentes, em sala de aula e que estavam atuando em cargos de gestão, iniciaram o curso, 88 concluíram os módulos e somente 62 receberam a certificação. Uma das queixas mais comuns em relação ao curso é que ele utilizou o sistema operacional Metasys, que não foi depois utilizado, já que a instituição de Ensino Superior global responsável instalou um outro sistema operacional nos equipamentos que foram entregues às escolas.

Os docentes criticaram também o fato das atividades de estudo serem postadas no ambiente virtual e-ProInfo e não disponibilizadas de forma impressa ou em outra versão, já que não possuíam tempo ou mesmo acesso à internet em casa, para fazer as atividades. Poucos NTE forneceram material impresso do curso aos cursistas. E o material impresso, quando oferecido, se limitava a tratar de informações técnicas sobre o laptop.

Os professores entrevistados consideraram como parte teórica dos cursos tanto as discussões sobre as teorias educacionais que fundamentam o trabalho docente quanto o conteúdo técnico para manuseio do sistema operacional Linux e seus aplicativos. Eles salientaram que pouco tempo foi destinado à discussão sobre as teorias educacionais e que precisariam de mais horas em cursos posteriores, quando estariam com maior experiência, que daria base para refletir sobre aplicações pedagógicas.

Segundo depoimentos, os professores possuem interesse em utilizar os laptops em suas aulas, mas alegam sentir necessidade de um suporte pedagógico 
e técnico para melhor uso do dispositivo, já que não possuem plena autonomia na resolução de eventuais problemas. Alegam também que possuem pouco tempo para o planejamento das atividades com o uso do laptop. Isso também é constatado por Santos (2010):

Os sujeitos entrevistados apontaram que os programas de formação docente estavam voltados para atender às necessidades mais imediatas de utilização dos laptops em sala de aula, bem como tinham como objetivo minimizar a falta de conhecimento técnico dos professores. No entanto tanto docentes como gestores consideraram que os programas de formação foram insuficientes em sua carga horária. (SANTOS, 2010, p. 193).

Enfim, a fragmentação das ações formativas dificulta - por parte do professor - o processo de apropriação das dimensões técnica e pedagógica de seu trabalho.

Echalar, Peixoto e Carvalho (2015) analisam relatos de professores da Educação Básica pública, destacando que a recusa destes a se submeterem a orientações e imposições governamentais, apontando questionamentos, renúncias e necessidades particulares ao seu processo formativo, pode representar resistência ao processo, que separa e distingue teoria e prática. Isto porque, se a alienação e a divisão em classes são estruturais, sua superação só poderá ocorrer a partir de uma radical revisão da lógica que a sustenta, explica e justifica. Essas manifestações docentes são, ao mesmo tempo, marcas da alienação e sinais de condições de possibilidades outras que se anunciam, constituindo-se, portanto, em construção coletiva e subjetiva de uma teoria que se insere na própria práxis.

Trata-se de uma racionalidade da práxis (VÁZQUEZ, 2011) que recusa os dualismos e as unilateralidades, visto que as contradições entre a aceitação do Programa e as queixas a ele não se constituem em aspectos mutuamente excludentes. Em outras palavras, a crítica ao dualismo idealista representa uma possibilidade de emancipação do sujeito alienado.

\section{PROUCA: uma solução para a exclusão digital?}

Os documentos do PROUCA adotam os termos "inclusão" e "exclusão" como uma oposição. Esta forma de tratar a questão é um equívoco, visto que 
esses termos não se opõem, mas se constituem em uma contradição, o que implica que eles se distinguem, mas se articulam de forma intrínseca. Para Sarian (2012), a inclusão e a exclusão são apresentadas, nos documentos oficiais do Programa, como oposição conceitual, de forma que o mundo incluído digitalmente "pertence à lógica da informatização da sociedade capitalista" (SARIAN, 2012, p. 134) e o mundo digitalmente excluído é aquele que projeta o sentido dessa lógica oposta e externa para o indivíduo que é excluído digitalmente.

A dinâmica que polariza esses conceitos nega o processo histórico de constituição do processo educativo e de formação do sujeito na contemporaneidade. Essa oposição suscita uma nova desigualdade social, a dos parcialmente excluídos ou dos recém-marginalizados. A igualdade jurídica em um contexto político de desigualdade social cria continuamente novos meios de exclusão e, por conseguinte, novos meios de incluir e de reintegrar os excluídos de forma degradante. (MARTINS, 2012).

A definição de inclusão digital, que toma como referência o nível de desenvolvimento tecnológico externo (países desenvolvidos), alimenta o ciclo vicioso no qual os países pobres ou em desenvolvimento se colocam em uma corrida sem fim, para o alcance de uma meta, que sempre é projetada para mais adiante: assim que um estágio tecnológico é alcançado um outro "mais avançado" se coloca como referência.

A lógica da inclusão-exclusão digital impõe um universo externo ao sujeito: aquele da falta. (SARIAN, 2012). A ilusão do excluir/incluir é marcada nos documentos e práticas formativas do PROUCA como se ter ou não o acesso ao aparato (laptop) pudesse diminuir as desigualdades sociais entre os sujeitos que compõem as escolas participantes do Programa.

Martins (2012, p. 32) assevera que "[...] a sociedade capitalista desenraiza, exclui, para incluir, para incluir de outro modo, segundo suas próprias regras, segundo sua própria lógica". Por essa razão, indicamos que um programa de inclusão que adota como referência a oposição entre ter ou não acesso acentua as desigualdades que anuncia dissolver.

No escopo de uma política neoliberal, verifica-se a manutenção da desigualdade social, sendo que a miséria e a servidão são fatores historicamente essenciais para a sobrevivência desse sistema. Nessa concepção, a exclusão se configura como uma das estratégias históricas de manutenção da ordem social, ou seja, de manutenção de distintas formas de desigualdade.

Mas os processos educativos aparecem nas políticas públicas como espaço de excelência para os processos de inclusão digital e, consequentemente, de democratização social. Isso porque as tecnologias digitais são capitalizadas pelos organismos internacionais como recursos para impor condicionalidades aos projetos socioeducacionais dos chamados países em desenvolvimento. 
A operacionalização da estratégia de inserção das tecnologias de informação e de comunicação no ambiente escolar é possível em razão das relações de dependência econômica, mas também em função da maneira como as tecnologias têm sido apropriadas simbolicamente, visto que são apresentadas como dispositivo funcional direcionado para a eficiência do processo de ensino e aprendizagem.

As políticas e os programas educacionais se baseiam no determinismo tecnológico, que postula que a tecnologia determina o progresso social. Esses programas também se fundamentam em uma visão determinista, quando consideram a tecnologia como um sistema autônomo que se desenvolve segundo uma lógica própria e que influencia seu contexto. (FEENBERG, 2004; PEIXOTO, 2012). Mas "[...] é preciso superar a dicotomia que antagoniza objetos técnicos e sujeitos sociais como aspectos autônomos. A tecnologia é uma produção sócio-histórica e inerente a toda ação humana. Assim, não é possível extrair dos objetos técnicos a sua dimensão cultural". (PEIXOTO, 2012, p. 290).

O PROUCA, com base nas políticas neoliberais que o fundamentam, nega os contextos socioculturais, ou seja, as condições objetivas de trabalho dos docentes. Assim, o Programa se configura a partir do projeto de sociedade ao qual se vincula, mantendo o dualismo entre a teoria e a prática, entre o particular e o universal.

É na contradição entre o interesse particular (do sujeito) e o interesse coletivo (da sociedade) que o Estado (representante do coletivo) reforça a contradição entre a forma privada de apropriação e o caráter social do processo de produção. Isso porque o PROUCA ressalta os interesses da classe já estabelecida como dominadora dos meios de produção, reforçando os interesses dessa classe ao manter seus vínculos de domínio sobre os menos favorecidos. (MARX; ENGELS, 2007).

$\mathrm{O}$ embate entre o interesse particular e o coletivo decorre da centralidade do capital. O dualismo entre teoria e prática resulta da segregação entre o trabalho intelectual e o manual como estratégia de alienação do trabalhador e dominação do capital.

Assim, entendemos que o PROUCA bem como os demais programas de inclusão digital via ambiente escolar são políticas que se centram na preparação para o mercado de trabalho. Além disso, percebemos que esses programas visam formar o consumidor de aparatos digitais, já que temos um mercado em franca expansão que necessita de sujeitos que dominem tais aparatos.

Desse modo, o professor não se reconhece em seu trabalho, não se sentindo sujeito e sim objeto. Na seção seguinte, abordaremos a alienação presente no processo formativo proposto pelo PROUCA, fruto da adesão a uma política neoliberal e, consequentemente, a uma formação instrumental. 


\section{A alienação que (de)forma o processo formativo docente}

As políticas públicas para a formação de professores no Brasil estão diretamente vinculadas às diretrizes dos órgãos de fomento internacional. (EVANGELISTA, 2013; MAUÉS, 2009).

Diversas pesquisas apontam que grupos de pesquisa das IES públicas se associam a Organizações Não Governamentais (ONG) ou empresas para apropriarem-se de recursos do Estado. Fato observado neste estudo, já que a Fundação Pensamento Digital e os grupos de pesquisa do GTUCA receberam recursos financeiros para fazer a formação dos professores e a avaliação das escolas da fase I do Programa.

A política neoliberal não considera a educação como um direito do cidadão, mas como um produto para o mercado, um espaço de "compra e venda", de produtividade, de meritocracia e de resultados. Desta maneira, a escola fica com a difícil incumbência de educar o cidadão com um mínimo de conteúdo e estrutura.

Corroborando a ideia de uma política de governo desarticulada e desinteressada pela melhoria efetiva da qualidade do processo educativo, percebemos que a formação dos professores se estrutura como um processo fragmentado e hierarquizado.

O documento "Formação Brasil" (BRASIL, 2009), que regula a formação docente para o PROUCA, indica as sete IES globais como responsáveis pela elaboração e as IES locais e NTE/NTM apenas como executores do Programa (Quadro 1). Cabe aos executores efetivar o que foi planejado nacionalmente e, aos professores e gestores da escola, o papel de fazer o curso e implementar a política na escola.

De tal modo, percebemos que o processo formativo dos docentes se deu por meio de uma divisão de trabalho, ou seja, de uma forma seccionada, conforme uma divisão do trabalho em que a atividade intelectual e técnica, a produção e o consumo são postos a indivíduos distintos. (MARX; ENGELS, 2007). A fragmentação e a hierarquização da força de trabalho docente contribuem para um processo de alienação dos professores, já que estes se tornam apenas os executores de ações sobre as quais deveriam possuir domínio da dimensão intelectual. (MARX, 2004).

Assim como os papeis formativos são distintos durante o processo de formação dos professores, os eixos tecnológico, pedagógico e teórico, como proposto no documento "Formação Brasill", também não são articulados. Os memoriais redigidos pelos professores que fizeram os cursos e o relato dos en- 
trevistados demonstram que os cursos são voltados essencialmente para o ensino do manuseio de alguns aplicativos disponíveis nos laptops, caracterizando uma formação instrumental.

Arce (2001), ao fazer a crítica à política neoliberal, salienta que - para essa perspectiva política - a formação se resume no aprender fazendo e em serviço, focando a atualização em parafernálias tecnológicas, domínio de algumas habilidades técnicas e manuseio de manuais e livros. Para tanto, a educação a distância é um caminho prático e eficaz. Assim, a formação ofertada pelo PROUCA em Goiás cumpre exatamente estes pressupostos: ser modular e em serviço, com muitas horas na modalidade a distância. São cursos centrados nos resultados, sendo aligeirados e pré-moldados, limitando-se a estudos de procedimentos e estratégias específicas para ensinar os conteúdos. Tais cursos se baseiam em uma concepção do trabalho do professor como eminentemente prático, voltado à aplicação de técnicas prontas e multiplicadas.

Tal concepção formativa reduz a tarefa docente à transmissão de informações. Esse ato transmissivo deve-se dar de forma eficiente e clara, desenvolvendo no aluno a capacidade de captar informações utilitárias e pragmáticas. Assim, não cabe ao professor acrescentar nada além do que já tenha sido ensinado nos cursos de formação. Ele é visto como um técnico, um prático que escolhe, dentre as opções a ele apresentadas, os melhores caminhos para a aprendizagem de seus alunos.

A metodologia a ser utilizada na formação de professores deve ser a mesma que ele irá aplicar posteriormente [...]. Consequentemente, este professor que deverá ensinar o aluno a "aprender a aprender" deverá também "aprender a aprender" durante a sua formação, por isso a categoria de prático-reflexivo ser usada com tanta propriedade. (ARCE, 2001, p. 266).

Os princípios pedagógicos do Programa se apresentam fundamentados no "desenvolvimento da inteligência" (BRASIL, 2009, p. 4), com vistas à autonomia e à ampliação do conhecimento sobre a realidade contemporânea, e propõem como estratégia a construção cooperativa do conhecimento, criando uma cultura intra e interescolas. Mas o processo formativo do PROUCA não condiz com essa proposição, visto que o trabalho pedagógico é apresentado como um disciplinamento social e produtivo, centrado no processo de "aprender a aprender" e não na formação intelectual crítica do docente. O processo formativo descrito é um meio de alienação do professor, pois não considera o trabalho como parte do modo de desenvolvimento intelectual do sujeito. 
Dessa forma, a propagada articulação entre teoria, prática e tecnologia camufla, na verdade, a precarização do trabalho docente, pois amplia a dicotomia entre teoria e prática e, com isso, aumenta as possibilidades de reprodução do capital, já que aprofunda a divisão entre capital e força de trabalho. Para Marx e Engels (2007, p. 15), a “[...] compreensão do processo de trabalho permite, ao mesmo tempo, a compreensão da origem da separação da teoria e da prática e das formas que permitem sua reconexão". Os autores ainda ressaltam que "[...] o caminho da razão é, portanto, o caminho do reconhecimento da cisão e de suas raízes; em seguida, de sua superação e do restabelecimento de sua unidade". (MARX; ENGELS, 2007, p. 12).

A formação docente proposta no contexto do PROUCA oferece um processo preponderante de reflexão na prática, por meio de "[...] conhecimento técnico ou de solução de problemas que orienta a atividade humana e manifesta-se no saber fazer”. (MIZUKAMI et al., 2002, p. 16). Essa reflexão, na prática, tem como foco de aprendizagem o conhecimento da técnica e a aceitação do recurso tecnológico no ambiente escolar. Mas nós entendemos que o processo formativo - mesmo quando em processo de formação continuada - não pode se limitar a preocupações de ordem prática, pois se sabe que o ambiente escolar é permeado por influências sociais, políticas e econômicas e uma infinidade de tensões que extrapolam os muros da sala de aula e da escola, estando presentes no cotidiano do trabalho docente.

De acordo com Pimenta e Ghedin (2006), a massificação da expressão "professor reflexivo" tem contribuído para que o professor não se engaje em práticas mais críticas, reduzindo-as a um fazer técnico ou rotineiro. Para os autores, o saber docente não é formado "apenas" da prática, mas é nutrido também pelas teorias da educação, pois são elas que propiciam aos professores os meios de compreender os contextos históricos, sociais, culturais, organizacionais e de si próprios como profissionais.

Assim como o trabalho docente é fragmentado, também se verifica que a atividade intelectual (conhecimento científico) e material (saber prático), a produção e o consumo, o gozo e o trabalho cabem a indivíduos distintos, sendo distribuídos desigualmente, contribuindo para aumentar a alienação dos trabalhadores. (MARX; ENGELS, 2007).

Observamos ainda que a disparidade entre os que possuem os meios de produção e os que vendem sua força de trabalho está cada vez mais acentuada e que o trabalho intelectual compete, cada vez mais, a um número menor de trabalhadores, assim como o trabalho instrumental está cada vez mais esvaziado de formação intelectual.

Assim, as práticas formativas docentes observadas no quadro da analisada política pública indicam a ausência de uma política de Estado e afirmam a 
existência de uma política de governo, cujos programas são desarticulados do contexto social brasileiro, atendem a fins financeiros e visam à manutenção das desigualdades. Neste sentido, são políticas para manutenção de uma inclusão excludente.

O discurso da inclusão, da igualdade entre as classes sociais, oculta a diversidade de contextos como se as diferenças econômico-sociais pudessem ser equacionadas por meio de ações jurídicas e burocráticas que conduzissem a uma condição universal justa e democrática. Esta ideia de universalidade desconsidera a particularidade, e, ao contrário de reduzir, estabelece distintas formas de ampliação da desigualdade social. O PROUCA propaga a ilusão de que as diferenças sociais e as desigualdades produzidas pela divisão social da sociedade capitalista serão solucionadas com a chegada dos laptops às escolas. Mas, segundo nossa compreensão, as possibilidades de intervenção efetiva na realidade em que vivemos e a busca de meios para a superação das desigualdades estão em um projeto educativo que coloque em questão o modelo social, econômico e político vigente.

\section{Considerações finais}

Dois temas emergem do tratamento da questão dos processos formativos docentes do PROUCA. Um, referente à formação de professores que, na atualidade, está centrada em uma perspectiva neoliberal. Ou seja, seu processo é baseado na racionalidade instrumental, havendo o esvaziamento do processo de formação cultural e intelectual do professor, cabendo a ele apenas a reprodução do que é aprendido em sua chamada capacitação. (EVANGELISTA, 2013).

A questão da inclusão digital via ambiente escolar, o outro tema fundamental nesta pesquisa, toma como foco o PROUCA, que é posto como resultado de políticas públicas vinculadas aos organismos multilaterais em nosso país, os quais visam à manutenção da desigualdade social por meio de um processo de inclusão excludente.

Reafirmamos, por isso, que a formação docente não pode prescindir de uma formação filosófica, histórica, social e política, bem como de uma densa fundamentação didático-metodológica, porquanto acreditamos que, para se formar um profissional capaz de compreender sua sala de aula e agir de forma significativa, é necessário teorizar as relações entre educação e sociedade, para atuar enquanto uma ação cidadã e que seus alunos possam ter acesso ao conhecimento historicamente construído pela humanidade de forma autônoma. 
Cremos que a relação entre a academia, a pesquisa acadêmica e o processo de formação de professores da escola pública brasileira precisa ser repensada, para que a universidade consiga, por meio de suas pesquisas e ações formativas, cumprir seu papel social. Consideramos a universidade como espaço possível para a atuação de intelectuais comprometidos com a construção de um país mais justo e igualitário, vislumbrando a luta pela educação pública de qualidade, pela profissionalização e valorização da docência, em contraposição ao processo alienante do mundo do capital.

Propomos, assim, o aprofundamento de estudos e o comprometimento com uma pesquisa que afirme a necessidade de participar da construção de uma racionalidade docente. (ECHALAR; PEIXOTO; CARVALHO, 2015). Uma pesquisa por meio da qual os professores sejam ouvidos a partir de um olhar diacrônico e histórico sobre as tecnologias e seus usos, discernindo os diferentes contextos e etapas de resistência que recobrem e constroem o trabalho docente.

Uma análise dos documentos que referenciam o PROUCA e de seu processo de implantação no estado de Goiás nos permitiu compreender como o Programa é marcado por condicionalidades econômicas. Tais marcas se refletem desde os aspectos operacionais de aquisição de equipamentos até o processo de formação de professores, deixando uma forte lacuna no que diz respeito ao seu fundamento pedagógico.

Por fim, o PROUCA revela uma articulação entre a política econômica global e as políticas de governo orientadas para o trabalho social no país. E essa articulação não almeja efetivamente a inclusão social, já que não busca solucionar a concentração de renda de sua população, mantendo a desigualdade social.

\section{REFERÊNCIAS}

ARCE, A. Compre o kit neoliberal para a educação infantil e ganhe grátis os dez passos para se tornar um professor reflexivo. Educação \& Sociedade, Campinas, v. 22, n. 74, p. 251-283, 2001.

BRASIL. Ministério da Educação. UCA - Projeto Um Computador por Aluno. Formação Brasil: projeto, planejamento das ações e cursos. Brasília: MEC/SEED, 2009.

CURY, C. R. J. A educação escolar, a exclusão e seus destinatários. Educação em Revista, Belo Horizonte, v. 48, p. 205-222, dez. 2008. 
ECHALAR, A. D. L. F. Formação de professores para a inclusão digital via ambiente escolar: o PROUCA em questão. 147 f. Tese (Doutorado em Educação) - Pontifícia Universidade Católica de Goiás, Goiânia, 2015.

ECHALAR, A. D. L. F.; PEIXOTO, J.; CARVALHO, R. M. A. de. Uma pesquisa com foco na racionalidade docente. In: ECHALAR, A. D. L. F.; PEIXOTO, J.; CARVALHO, R. M. A. de. (Org.). Ecos e repercussões dos processos formativos nas práticas docentes mediadas pelas tecnologias. A visão de professores da rede pública da Educação Básica do estado de Goiás sobre os usos das tecnologias na educação. Goiânia: Kelps, 2015. p. 117-125.

EVANGELISTA, O. Qualidade da educação pública: estado e organismos multilaterais. In: LIBÂNEO, J. C.; SUANNO, M. V. R.; LIMONTA, S. V. (Org.). Qualidade da escola pública: políticas educacionais, didática e formação de professores. Goiânia: CEPED / Kelps / Gráfica e Editora América, 2013. p. 13-46.

FEENBERG, A. (Re)penser la tecnhique. Vers une technologie démocratique. Trad. Anne-Marie Dibon. Paris: Éditions La Découverte, 2004.

FIGUEIREDO, A. D. L. PROUCA em Goiás: concepções pedagógicas e processos formativos. Projeto de pesquisa. Goiânia: PUC Goiás, 2013.

FREITAS, L. C. Os reformadores empresariais da educação: a consolidação do neotecnicismo no Brasil. In: FONTOURA, H. A. da. (Org.). Políticas Públicas, Movimentos Sociais: desafios à Pós-Graduação em Educação em suas múltiplas dimensões. Rio de Janeiro: Anped Nacional, 2011. (Coleção ANPED Sudeste, Livro 3). p. 72-90.

GOMES, A. C. F. G. Conectividade para utilização de laptops educacionais. 147 f. Dissertação (Mestrado em Educação) - Universidade Federal Fluminense, Rio de Janeiro, 2010.

MARQUES, A. C. da C. O Projeto Um Computador por Aluno - UCA: reações na escola, professores, alunos, institucional. 93 f. Dissertação (Mestrado em Educação) Universidade Federal do Paraná, Curitiba, 2009.

MARTINS, J. de S. Exclusão social e a nova desigualdade. São Paulo: Paulus, 1997.

MARTINS, J. de S. Exclusão social e a nova desigualdade. 5. reimp. São Paulo: Paulus, 2012. (Coleção Temas de Atualidade).

MARX, K. Manuscritos econômico-filosóficos. Tradução de: RANIERI, J. São Paulo: Boitempo, 2004.

MARX, K.; ENGELS, F. A ideologia alemã. São Paulo: Boitempo, 2007.

MAUÉS, O. C. A agenda da OCDE para a educação. In: GARCIA, D.; CECÍLIO, S. (Org.). Formação e profissão docente em tempos digitais. Campinas: Alínea, 2009. p. 15-39. 
MIZUKAMI, M. da G. N.; REALI, A. M. de M.; REYES, C. R.; MARTUCCI, E. M.; LIMA, E. F.; TANCREDI, R. M. S. P.; MELLO, R. R. Escola e aprendizagem da docência: processos de investigação e formação. São Carlos: EdUFSCar, 2002.

MOREIRA, S. R. da S. Análise de reações de professores face à introdução do computador na educação: o caso do projeto UCA - Um Computador por Aluno - no Colégio Estadual Dom Alano Marie Du’ Noday (TO). 112 f. Dissertação (Mestrado em Educação) - Universidade de Brasília, Brasília, 2010.

PEIXOTO, J. Tecnologia e mediação pedagógica: perspectivas investigativas. In: KASSAR, M. de C. M.; SILVA, F. de C. T. (Org.). Educação e pesquisa no Centro-Oeste: políticas públicas e formação humana. Campo Grande: UFMS, 2012. v. 1. p. 283-294.

PIMENTA, S. G.; GHEDIN, E. (Org.). Professor reflexivo no Brasil: gênese e crítica de um conceito. 4. ed. São Paulo: Cortez, 2006.

SANTOS, M. B. F. dos. Laptops na escola: mudança e permanência no currículo. 215 f. Dissertação (Mestrado em Educação) - Universidade do Estado de Santa Catarina, Florianópolis, 2010.

SARIAN, M. C. A injunção ao novo e a repetição do velho: um olhar discursivo ao Programa Um Computador por Aluno (PROUCA). 274 f. Tese (Doutorado em Linguística) - Universidade Estadual de Campinas, Campinas, 2012.

VÁZQUEZ, A. S. Filosofia da práxis. 2. ed. Buenos Aires: Consejo Latinoamericano de Ciencias Sociales - Clacso. São Paulo: Expressão Popular, 2011.

Texto recebido em 30 de março de 2016. Texto aprovado em 21 de abril de 2016. 